\title{
Magnesium Based Materials: Nature's Choice to Relieve Strain on Environment and For Welfare of Living Beings
}

\author{
Gupta $\mathbf{M}^{*}$ \\ Department of Mechanical Engineering, National University of Singapore (NUS), Singapore
}

Submission: April 18, 2017; Published: May 11, 2017

*Corresponding author: Gupta M, Department of Mechanical Engineering, National University of Singapore (NUS), Singapore, Email: mpegm@nus.edu.sg

\section{Short Communication}

The responsibility of a responsible researcher and an entrepreneur in current context is to promote technology to enhance the current health of environment and the living beings on planet earth. While the technologies developed so far were targeted largely to improve human comfort they failed in containing contamination of water bodies, land and hence the health of living organisms. Accordingly, what we witness today is global climate changes creating havocs in practically all parts of world inflicting financial losses worth billions of dollars besides affecting the life, livelihood and health of millions of people. Unless such changes are challenged and reversed by researchers and entrepreneurs, our future generations will definitely have a bleak future and we will be partly responsible for that.

From a materials engineer perspective, the challenge is to bring in materials in mainstream that are not toxic, degradable, recyclable and capable of reducing emission of greenhouse gases and hence the carbon footprint. Magnesium based materials, including composites fit in this category. Magnesium positioned in group $2 \mathrm{~A}$ of the periodic table is the lightest metal ( $235 \%$ lighter than aluminum) that can be used for structural applications in engineering sectors including automobile, aerospace, space, defense, electronics, sports and biomedical sectors. It is also one of the most abundant elements in earth crust, oceans and in universe ensuring that magnesium technology, if properly nurtured and utilized, can last for many centuries to come.

Comparing magnesium with other commonly used elements such as aluminum (most widely used metal based on volume) and iron (most widely used metal by weight), it can be observed and realized that magnesium exhibit lowest melting point $\left(650^{\circ} \mathrm{C}\right.$-less energy required for melting and casting) and superior specific strength and comparable specific modulus. Besides, it also exhibit excellent castability, machinability, damping and electromagnetic shielding capabilities. Some of these attributes ensures high manufacturing and production speeds which are important for saving time and cost for industrial sectors.
Looking into past, magnesium and its alloys were extensively used in 1940s in defense (bullets and bombs), aerospace (Convair XC-99 airframe) and automobile (Beetle car) sectors, however, their use faded away except for some specialized applications. In 1990s, the progressive worsening of climate, toxification of land and water bodies and the concept of sustainability redirected the attention of politicians and researchers to relook into magnesium based materials as a viable option for light weighting and to address above mentioned issues. First decade of 21st century witnessed the rapid growth in research activities primarily targeted to develop processing routes, alloys, composites and surface protection techniques related to magnesium based materials for bringing them in mainstream of materials. This period also saw the emergence of China, South Korea, Germany and Japan as the main players in magnesium technology. The cumulative efforts made by researchers worldwide dispelled the myths and apprehensions about magnesium and brought the positive image of magnesium based materials with FAA approving there use in year 2015 in airplanes provided they meet certain flammability criterion. Parallel to this development was the simultaneous evolution of magnesium as biomaterial targeted as potential orthopedic implant. Magnesium being a nutritional element for humans (an average human needs 250$400 \mathrm{mg}$ per day) and its elastic modulus being closest to bone makes it an ideal choice as an implant. It is currently used in pin and screw portfolio with positive results obtained so far from human subjects.

In order to further enhance the usage of magnesium based materials, challenges remain. The number of alloys with wide spectrum of properties is limited when compared to aluminum based alloys and hence need to expand. As magnesium is one of the most electrochemically active element, its corrosion resistance needs to be improved through compositional adjustment and surface enhancement techniques. These issues are partly addressed, for example, through the use of rare earth elements 
but more work is required. To broaden the usage of magnesium based materials, composite technology provides another option to enhance targeted properties depending on end applications. As an example, judicious use of reinforcement at nano-length scale can enhance ambient and high temperature strength, ductility, creep resistance, wear resistance, damping, fatigue, ignition and dry and wet corrosion resistance of magnesium. Similarly, use of metastable/amorphous reinforcement provides another option to enhance hardness, strength and tribological response of magnesium even in micron length scale without significantly affecting ductility unlike their ceramic counterparts. Yet another option is to use hollow reinforcement such as cenospheres (hollow fly ash particles- an industrial waste) which have shown excellent capability to enhance compressive deformation of magnesium. These materials are commonly known as syntactic foams and are targeted for impact prone applications.

While multiple options are available in open literature for expanding the use of magnesium based materials, the bottleneck appears to be the adoption of such technology and up scaling to industrial level. Progress is being made but the pace is slow. It is sincerely hoped that such challenges will be taken up by investors and industrialists to relieve the technological stress imposed on planet earth and its inhabitants.

\begin{tabular}{l} 
Your next submission with Juniper Publishers \\
will reach you the below assets \\
- Quality Editorial service \\
- Swift Peer Review \\
- Reprints availability \\
- E-prints Service \\
- Manuscript Podcast for convenient understanding \\
- Global attainment for your research \\
- Manuscript accessibility in different formats \\
( Pdf, E-pub, Full Text, Audio) \\
- Unceasing customer service \\
Track the below URL for one-step submission \\
https://juniperpublishers.com/online-submission.php \\
\hline
\end{tabular}

